\section{Human}

Development
Chae, D. 270

Chung, K. 270

Killen, M. 257

Niwa, E.Y. 270

Pauker, K. 325

Rivas-Drake, D. 293

Rogers, L.O. 270

Ruck, M.D. 257
Tai, C. 325

Umaña-Taylor, A.J. 293

Verkuyten, M. 311

Yee, K.M. 257

Yip, T. 270

\title{
Subject Index Vol. 65, No. 5-6, 2021
}

Anti-Blackness 270

Anti-racism socialization 270

Black Lives Matter 270

Development 257

Developmental interventions 325

Ecological systems theories 270

Ethnicity 257

Ethnic-racial identity 293

Group identity 311

Ingroup bias 311

Intergroup relations 325

Intersectionality 270

Lay theories 257, 325
Mindsets 325

Prejudice 257, 325

Racial marginalization 293

- socialization 270

Racism 257, 270

Resistance 270

Risk and resilience 293

Social identity approach 311

- justice 257

Stereotyping 325

White supremacy 270

Youth development 293 